LETTER TO THE EDITOR

\title{
Immortal time bias in retrospective analysis: comment on 'Efficacy and safety of long-term treatment with lenalidomide and dexamethasone in patients with relapsed/refractory multiple myeloma'
}

Blood Cancer Journal (2015) 5, e283; doi:10.1038/bcj.2015.4; published online 27 February 2015

We read with interest 'Efficacy and safety of long-term treatment with lenalidomide and dexamethasone in patients with relapsed/ refractory multiple myeloma'. ${ }^{1}$ Dimopoulos et al. reported a retrospective post-hoc pooled analysis by using the data from two randomized trials, MM-009 and MM-010, which showed improved outcomes in patients with relapsed/refractory multiple myeloma treated with lenalidomide and dexamethasone. An important finding in Dimopoulos's report is the association between humoral improvement (uninvolved immunoglobulin A) and the long-term benefit of therapy. It shows humoral responders had better progression-free survival and overall survival compared with humoral nonresponders, in Figure 2. However, humoral response could occur at anytime from cycle one to ten. If the data was analyzed by using a log-rank test or time-independent Cox regression model, it is likely that an 'immortal time bias' could interfere with this result. $^{2-5}$

'Immortal time' refers to a time interval during the follow-up period in which the outcome could never occur because of exposure definition. For example, death cannot occur in the first 5 months of follow-up, in patients who had humoral response after at least six cycles (of each 28-day cycle). In conventional survival analysis, the immortal time bias can confer a spurious survival advantage to the responder group if the response is measured in the middle of the follow-up period but not at the beginning of the trial. Humoral improvement might predict the outcomes of the patients with multiple myeloma. Nevertheless, the result should be analyzed using time-dependent analysis, ${ }^{2,5}$ such as Cox regression with response status as a time-dependent covariate. We look forward to see such reanalysis of the original data.

\section{CONFLICT OF INTEREST}

The authors declare no conflict of interest.

\section{ACKNOWLEDGEMENTS}

This work is supported by research grants of Far Eastern Memorial Hospital (FEMH-2015-C-0312).

P-Y Hsieh ${ }^{1}$, C-J Liu ${ }^{2,3,4}$ and C-J Teng ${ }^{1,2,3}$

${ }^{1}$ Division of Oncology and Hematology, Department of Medicine, Far Eastern Memorial Hospital, New Taipei City, Taiwan; ${ }^{2}$ School of Medicine, National Yang-Ming University, Taipei, Taiwan; ${ }^{3}$ Institute of Public Health, National Yang-Ming University, Taipei, Taiwan and

${ }^{4}$ Division of Hematology and Oncology, Department of Medicine, Taipei Veterans General Hospital, Taipei, Taiwan E-mail: cjteng.tw@gmail.com

\section{REFERENCES}

1 Dimopoulos MA, Swern AS, Li JS, Hussein M, Weiss L, Nagarwala Y et al. Efficacy and safety of long-term treatment with lenalidomide and dexamethasone in patients with relapsed/refractory multiple myeloma. Blood Cancer J 2014; 4: e257.

2 Levesque LE, Hanley JA, Kezouh A, Suissa S. Problem of immortal time bias in cohort studies: example using statins for preventing progression of diabetes. BMJ 2010; 340: b5087.

3 Shariff SZ, Cuerden MS, Jain AK, Garg AX. The secret of immortal time bias in epidemiologic studies. J Am Soc Nephrol 2008; 19: 841-843.

4 Lash TL, Cole SR. Immortal person-time in studies of cancer outcomes. J Clin Oncol 2009; 27: e55-e56.

5 Suissa S. Immortal time bias in pharmaco-epidemiology. Am J Epidemiol 2008; 167: 492-499.

(i) This work is licensed under a Creative Commons Attribution 4.0 International License. The images or other third party material in this article are included in the article's Creative Commons license, unless indicated otherwise in the credit line; if the material is not included under the Creative Commons license, users will need to obtain permission from the license holder to reproduce the material. To view a copy of this license, visit http://creativecommons.org/licenses/ by/4.0/ 